\title{
Understanding the Relationship Between Amphetamines and Psychosis
}

\author{
Eline Borger Rognli ${ }^{1,2,3}$ • Jørgen G. Bramness ${ }^{1}$
}

Published online: 28 September 2015

(C) Springer International Publishing AG 2015

\begin{abstract}
Use of amphetamine and methamphetamine (hereafter amphetamines) can cause acute psychotic symptoms and may also contribute to persistent psychotic conditions such as schizophrenia. Still, much remains uncertain about the mechanisms and nature of this relationship. In this paper, we review certain aspects of this relationship, with particular emphasis on papers published during the past 3 years. A review of the literature reveals that, in addition to the established knowledge that amphetamines can cause acute psychotic symptoms, more evidence has emerged that amphetamines may play a role also in the pathogenesis of schizophrenia. Determining causality for the amphetamine-psychosis association has, however, proven complicated. Reversed causality may be the case, as may be the notion that both use of amphetamines and psychosis reciprocally affect each other with deteriorating effects on both conditions. Clinical features like sensitization to amphetamines precipitating psychosis, that even amphetamineinduced psychosis may persist, and diagnostic transition from amphetamine-induced to primary psychosis suggest a continuous and mutual interaction between individual vulnerability, amphetamine exposure, and psychosis. The high transition rates also point to amphetamine-induced psychosis as a major
\end{abstract}

This article is part of the Topical Collection on Dual Diagnosis

Eline Borger Rognli

e.b.rognli@medisin.uio.no

1 Norwegian Centre for Addiction Research (SERAF), Institute of Clinical Medicine, University of Oslo, Box 1039, Blindern 0315, Oslo, Norway

2 Division of Mental Health and Addiction, Oslo University Hospital, Box 4950, Nydalen 0424, Oslo, Norway

3 Norwegian National Advisory Unit on Concurrent Substance Abuse and Mental Health Disorders, Box 104, 2381 Brumunddal, Norway risk factor for primary psychosis. Mortality rates are high for both psychosis and use of amphetamines, and we lack highquality treatment guidelines to apply when these two conditions occur together. Amphetamine-induced psychosis may be more affiliated with primary psychosis than previously assumed. Some clinical implications are suggested.

Keywords Amphetamine - Psychosis · Schizophrenia · Substance-induced $\cdot$ Stimulants $\cdot$ Methamphetamine

\section{Background}

Amphetamine was first synthesized in 1887 [1], followed shortly after by methamphetamine [2]. The stimulating effects of amphetamine were documented scientifically in 1935 [3], and the potential for excessive use and psychosis was described three years later [4]. During the following decades, the substances were used by soldiers in combat to prolong wakefulness, and they were also marketed to the normal population to increase energy and reduce weight. Technological improvements in mass production and purity have made amphetamine and methamphetamine (hereafter referred to as amphetamines) increasingly available. After cannabinoids, amphetamines are the second most commonly used class of illegal drugs, with the most recent global estimates of past-year users at between 14 and 55 million individuals [5]. Based on reports from nine countries in Western and Eastern Europe, North America, Australia, and Southeast Asia, the prevalence of dependence is between 0.1 and $0.73 \%$ [6]. Use of amphetamines can cause acute psychotic symptoms such as hallucinations and persecutory delusions and a condition described as MA-induced psychosis [7] or methamphetamineassociated psychosis (MAP) [8•]. Though the difficulty in differentiating MAP from primary psychosis has been 
acknowledged [8•], the association between amphetamine use and schizophrenia is less clear.

\section{Introduction}

The aim of this paper is to provide an overview of the relationship between use of amphetamines and psychosis. We will differentiate between single psychotic symptoms which do not fulfil the criteria for a psychosis diagnosis, amphetamineinduced psychosis, and primary psychosis such as schizophrenia (DSM-IV), and we describe how these conditions are related to the use of amphetamines. We aim to illustrate the complexity and the still incomplete understanding of the amphetamine-psychosis association. Mortality and its association with psychosis and the use of amphetamines will be emphasized as the risk of this outcome should guide treatment. Clinical implications will be discussed.

\section{Use of Amphetamines and Acute Psychotic Symptoms}

The association between amphetamines and acute psychosis was demonstrated in laboratory studies in the 1960s and 70s, where healthy volunteers were exposed to increasingly higher doses of amphetamine, while psychotic symptoms were noted [9-11]. The trend was that high doses and long periods of exposure increased the probability of experiencing psychotic symptoms.

Recreational methamphetamine use increases the risk of experiencing psychotic symptoms [12], with dependent users at a higher risk [13]. Among chronic methamphetamine users, high levels of use in the previous month have been shown to be associated with up to five times increased risk compared to no-users [14•]. The most common single psychotic symptoms in response to use of amphetamines are persecutory delusions and auditory hallucinations [15-17].

Several studies have found a dose-response relationship between precipitation of psychotic symptoms and the amount of amphetamines administered in laboratory investigations [9, 11], the amount used during the previous month [14•], age of onset [18-20], years of use [21,22], and severity of the SUD [23]. Both the probability of experiencing psychotic symptoms and the severity and duration of the psychosis are affected by these exposures. Other studies have not been able to reproduce the dose-response relationship regarding age of onset and years of use [24, 25], and not all the individuals in the early clinical studies developed psychotic symptoms [9, 10]. One study indicated a trend for a relationship between level of metabolites of amphetamines in blood and urine and severity of psychotic symptoms [26]. This was interpreted as a positive finding, but others have failed to replicate this finding
[27•]. The evidence thus points to a dose-response relationship of some sort, but the relationship is not unequivocally defined and does not hold true for all cases.

\section{Use of Amphetamines and Primary Psychosis}

The relationship between use of amphetamines and psychosis has been researched in Asian studies, particularly in Japan, a country with decades of major amphetamine abuse problems. A growing body of evidence indicates that chronic methamphetamine use may gradually lead to development of a psychotic state similar to paranoid schizophrenia [28-31]. Interviews with individuals with methamphetamine-induced psychosis conducted after more than 6 months of abstinence reveal that a majority still suffer from psychotic symptoms and depressed mood [32]. This has been attributed to sensitization following long-term methamphetamine use and is characterized by enhanced vulnerability to relapse of psychosis and a development from non-psychotic to pre-psychotic to a severely psychotic state [33].

Also outside of Japan, amphetamines are increasingly considered for their role in the pathogenesis of schizophrenia [34]. A prospective register study from California found that patients who had been hospitalized for amphetamine-related conditions had nine times higher risk of developing schizophrenia, compared to a reference group of individuals hospitalized for appendicitis [35••]. When thorough diagnostic interviews with users of amphetamines are carried out, a small proportion $(10 \%)$ meets the criteria for lifetime primary psychotic disorder [20].

There is less evidence of a dose-response relationship to primary psychosis, but younger age $[36 \bullet \cdot]$ and more years of use [19] increase the risk of amphetamine-induced psychosis developing into schizophrenia.

\section{Causality}

For a causal relationship between the use of amphetamines and psychosis to be established, the use of amphetamines must predate the psychosis. The very name "amphetamine-induced psychosis" implies causality. As described above, a temporal cause-effect for exposure and acute psychosis, at least in the vulnerable, is well documented and relatively uncontroversial. However, there is a possibility that vulnerable individuals or individuals in the prodromal phase are more prone to use amphetamines, which then again exacerbates the psychosis. The validity of the concept "substance-induced" psychosis has indeed been criticized for over-interpreting causality, and the term "substance-associated" psychosis has been suggested as a more precise concept [37], a recommendation followed by some $[8 \cdot, 38]$. It should also be stressed that a diagnostic 
criterion for substance-induced psychosis is that the symptoms exceed the expected effects of intoxication and withdrawal, evaluated in relation to the particular substance and the amount used (DSM-IV). We question whether the term "amphetamine-induced psychosis" takes this into account sufficiently.

The questioning of causal direction is even more relevant when we consider primary psychosis. Up to $50 \%$ of individuals with schizophrenia report coexisting SUD [39, 40]. Advances in neurobiology suggest that the neuropathology of schizophrenia affects the neural circuitry mediating drug reward, making these individuals highly vulnerable for developing addiction [41]. Chambers and colleagues have described a hypothesis for the neurochemical mechanisms, where abnormalities in hippocampal-cortical function in schizophrenia result in hyper-reactivity to dopamine release [42]. Thus, the substance-use disorders occurring in patients with schizophrenia may be understood as a symptom of the disease or as a symptom occurring in parallel with the disease. A somewhat different hypothesis is that mentally ill individuals use substances to relieve symptoms and distress [43]. This hypothesis of self-medication thus assumes a causal direction similar to that of Chambers and colleagues but with different explanatory mechanisms. The individual experience of self-medication may be true even if the disease deteriorates following substance use.

In the case of primary psychosis, about one third of those hospitalized for first-episode schizophrenia have had a substance-use disorder prior to the hospitalization [44-46], allowing for the explanation that substance use precipitated the primary psychosis. Substance abuse also seems to lead to earlier onset of schizophrenia [45, 47]. However, determining causality between two conditions based on which was observed first may be misleading. Schizophrenia is a disease of slow progression, often with years between the first subclinical symptoms and the full-blown psychosis. As a consequence, substance use and psychosis may mutually exacerbate each other over a long period of time, making it difficult to conclude that one condition caused the other.

Many studies show that apart from nicotine, cannabis and alcohol are the most commonly abused substances for patients in treatment for schizophrenia, followed by stimulants [40, 44-46, 48-50]. A meta-analysis found pooled estimates of lifetime stimulant-use disorders in people with psychotic disorders to be $8.9 \%$, with a $95 \%$ confidence interval of 7.4-10.5\% $[51 \bullet]$. These figures are clearly higher than those of the average population, where global estimates range from 0.3 to $1.3 \%$ [6]. Two things were striking in the meta-analysis: (a) there was a close relationship between this variance and that of the general populations (a variation in rate, but a relatively similar relationship to population use across counties) and (b) the relationship had been constant over many years. Also, there was a close relationship between cannabis use and stimulant use.

\section{Other Factors}

Several factors have been shown to affect the relationship between use of amphetamines and psychosis. Users of amphetamines who, in childhood, experienced adverse events [38] or have had many ADHD-symptoms [52] have higher risk of experiencing amphetamine-induced psychosis than users without such risks. Psychiatric familial morbidity increases the probability and duration of amphetamine-induced psychosis $[52,53]$. Major depressive disorder occurs more often among users of amphetamines with psychosis compared to those without psychosis $[18,54]$ and more often among users with persistent psychotic symptoms versus those with brief symptoms [22]. Antisocial personality disorder is more prevalent among users of amphetamines with psychosis than among those without [18, 54]. Also, amphetamines cause prolonged wakefulness, and lack of sleep may induce psychosis-like symptoms [55].

Most people with psychosis, who use stimulants, also use cannabis, and cannabis is the most commonly used illicit drug among first-episode schizophrenia cases [40, 44-46, 48-50]. A recent review of stimulant-use disorders in people with psychosis found that cannabis use was the variable that most strongly correlated with stimulant use [51•]. Cannabis and methamphetamine have been suggested as the two most important drugs involved in the pathogenesis of psychosis and schizophrenia [34]. As the effect of cannabis, to a certain extent, counters that of amphetamines, users often take it to end amphetamine binges. Studies on psychosis in users of amphetamines seldom report on concurrent cannabis use. Given that cannabis often accompanies the use of amphetamines, it is uncertain to what extent the effect of cannabis might have influenced the evidence on the association between amphetamines and psychosis.

\section{Scientific Taxonomy Versus Clinical Reality}

Amphetamine-induced psychosis and schizophrenia are almost impossible to tell apart in the acute phase [27•]. The similarities are so pronounced that stimulant psychosis has been suggested as a model psychosis for schizophrenia [10, 15, 56-58]. Still, a review of stimulant psychosis found that, compared to schizophrenia, stimulant psychosis had a lower age of onset, fewer negative symptoms, more paranoid themes, and more commonly included hallucinatory experiences [59]. This study did, however, only include cocaineinduced psychosis. Higher prevalence of hallucinations in substance-induced psychosis has been supported by others [60], but negative symptoms have also been found to be prevalent in methamphetamine psychosis [15].

According to the Diagnostic and Statistical Manual of Mental Disorders, Fourth Edition (DSM-IV), an episode of psychosis is to be considered primary if the psychotic symptoms 
persist at least 1 month after the cessation of intoxication or acute withdrawal [61]. In the diagnostic tradition of Japan, psychotic symptoms following methamphetamine may remain for months and even years after abstinence. This is called "chronic methamphetamine psychosis" [62] or "persistent type" [32, 33]. The proportion of "persistent type" methamphetamine psychosis in the first, second, and third epidemics of methamphetamine use in Japan were respectively 24, 18, and $41 \%$ [33]. Also outside Japan, the long-lasting symptoms have been observed; one third had psychotic symptoms in a 6-month follow-up in a Canadian study [22], and $9 \%$ had symptoms for more than 1 month in an Iranian study [17]. Even if we cannot be totally sure we are talking about the same thing, the "persistent" or "chronic" psychosis after the intake of amphetamines would probably be viewed, in a western perspective, as primary psychosis precipitated by the use of amphetamines. Also, the limit of 1 month as differentiating between psychoses from amphetamines and primary psychosis may seem arbitrary [17, 22, 33].

Studies following this diagnostic practice show a conversion from drug-induced to primary psychosis over time. A study using the Psychiatric Research Interview for Substance and Mental Disorders (PRISM) [63] found a $25 \%$ 1-year conversion rate, but this study did not differentiate between substances [64]. A register-based study found the 8-year cumulative risk of receiving a schizophrenia spectrum diagnosis to be $30 \%$ for those with initial amphetamine-induced psychosis [36••], while a clinical 6-year follow-up after first hospitalization for methamphetamine psychosis resulted in $22 \%$ being diagnosed with schizophrenia [19]. Comparable estimates have been found in other studies (Table 1).
The boundaries between the diagnostic entities are thus not clear-cut. The similarities in the acute phase, the possibility of reversed causality, the persistent psychotic symptoms, and the high transition rates from amphetamine-induced psychosis to schizophrenia point to ambiguities of the taxonomy. Or, perhaps more precisely suggest that we have not yet established concepts and understandings that fully cover the complexity of the relationship between amphetamines and psychosis. On this basis, we have offered a more dynamic understanding of the relationship; suggesting that amphetamine-induced psychosis is best understood in a stress-vulnerability paradigm [65•]. Within this understanding, the use of amphetamines is only one of many factors that may increase an individual's susceptibility for psychosis. We argue, therefore, for a more integrated understanding of primary and amphetamine-induced psychosis. The neurotoxic effects of amphetamines and the effects of sensitization might explain why, for some individuals, psychosis occurs increasingly frequently after exposure to amphetamines. After some time, psychosis may be precipitated in response even to very small doses of the drug or to non-drug-related environmental stressors $[28,29,66]$. This is in line with the general psychosis field, which moves away from a dichotomous categorization of psychosis as something that is either present or not to a more continuous understanding $[67,68]$.

\section{Mortality}

Use of amphetamines increases the risk of death, with standardized mortality rates (SMR) ranging from 4.1 [69] to 6.0

Table 1 Studies investigating the transition from substance-induced psychosis to primary psychosis

\begin{tabular}{|c|c|c|c|c|c|c|}
\hline Author, year & $N$ & $\begin{array}{l}\text { Follow-up } \\
\text { time }\end{array}$ & Substances & Conversion rate & $\begin{array}{l}\text { Risk factors for } \\
\text { conversion }\end{array}$ & Death rate \\
\hline $\begin{array}{l}\text { Whitty et al., } \\
2005 \text { [86] }\end{array}$ & 11 & 4 years & Not reported & $64 \%$ & $\begin{array}{l}\text { Not measured for the SIP } \\
\text { group in particular }\end{array}$ & $9 \%$ \\
\hline $\begin{array}{l}\text { Caton et al., } \\
2007[64]\end{array}$ & 319 & 1 year & Not reported & $25 \%$ & $\begin{array}{l}\text { Poorer premorbid functioning } \\
\text { Less insight into psychosis } \\
\text { Greater family mental illness }\end{array}$ & $0.3 \%$ \\
\hline $\begin{array}{l}\text { Crebbin et al., } \\
2009 \text { [87] }\end{array}$ & 35 & 7 years & $\begin{array}{l}\text { All were users of multiple } \\
\text { substances. Cannabis } \\
\text { was used by } 83 \% \text {, } \\
\text { amphetamine by } 57 \% \text {, } \\
\text { and alcohol by } 49 \%\end{array}$ & $\begin{array}{l}29 \% \text { for all } \\
\text { substances } \\
\text { together }\end{array}$ & $\begin{array}{l}\text { Longer duration of index } \\
\text { hospitalization } \\
\text { Higher number of admissions }\end{array}$ & $3 \%$ \\
\hline $\begin{array}{l}\text { Pedrós et al., } \\
2009 \text { [88] }\end{array}$ & 8 & 2 years & Not reported & $13 \%$ & $\begin{array}{l}\text { Not measured for the SIP } \\
\text { group in particular }\end{array}$ & Not reported \\
\hline $\begin{array}{l}\text { Kittirattanapaiboon } \\
\text { et al., } 2010 \text { [19] }\end{array}$ & 449 & 7 years & Methamphetamine & $22 \%$ & $\begin{array}{l}\text { Early MA use } \\
\text { Frequent brain pathology } \\
\text { More frequent childhood } \\
\text { learning problems }\end{array}$ & $8 \%$ \\
\hline $\begin{array}{l}\text { Niemi-Pynttäri } \\
\text { et al., } 2013 \text { [36••] }\end{array}$ & $\begin{array}{l}825 \text { amphetamine } \\
\text { users }\end{array}$ & 8 years & $\begin{array}{l}\text { Cannabis, amphetamine, } \\
\text { alcohol, opioids, } \\
\text { sedatives, hallucinogens }\end{array}$ & $\begin{array}{l}30 \% \text { for } \\
\text { amphetamine }\end{array}$ & Younger age & Not reported \\
\hline $\begin{array}{l}\text { Medhus et al., } \\
2015[77 \bullet]\end{array}$ & 12 & 6 years & Amphetamine & $33 \%$ & $\begin{array}{l}\text { Homelessness } \\
\text { Fewer hallucinations }\end{array}$ & $25 \%$ \\
\hline
\end{tabular}


[70]. The increased mortality has been attributed to intoxications of amphetamines alone $(17 \%)$ or amphetamines combined with other substances (51\%), unnatural deaths such as accidents, suicide and homicide (12\%), and cardiovascular causes $(20 \%)$ [71]. An explanatory factor for the cardiovascular events could be the prolonged QTc-time observed in users of amphetamines [72, 73].

People with schizophrenia die on average 25 years earlier than the normal population, with $60 \%$ of the deaths being attributable to medical conditions such as cardiovascular and pulmonary diseases [74]. The mortality gap for schizophrenia relative to the general population has increased over the past three decades, suggesting that population improvements in lifestyle and health have not benefited this already disadvantaged group [75]. It has also been suggested that the weight gain and metabolic syndrome associated with secondgeneration antipsychotic drugs have contributed to the high mortality rates $[75,76]$.

The increased mortality rates for both users of amphetamines and for patients with schizophrenia raise some important questions about cardiovascular health, medication, and mortality for patients suffering from both amphetamine addiction and psychosis. This area is poorly investigated. Few studies report on the mortality among patients with amphetamineinduced psychosis. In a study from Thailand, 449 patients with first hospitalization for methamphetamine psychosis were followed for 6.5 years, and the researchers encountered the surprising secondary finding that 92 individuals $(8.2 \%)$ had died during follow-up with a yearly death rate of $1.3 \%$ [19]. An even higher death rate was found in a Norwegian study [77•].

\section{Treatment of Amphetamine-Induced Psychosis}

In the acute phase, treatment for amphetamine-induced psychosis aims at reducing confusion and agitation and inducing sleep, as is the case with acute schizophrenia. A recent review on treatment of toxicity of amphetamine recommended the use of antipsychotics, benzodiazepines, and beta-blockers to control psychosis, agitation, and hyper-adrenergic symptoms [78]. The Australian guidelines for the treatment of acute methamphetamine-induced psychosis recommend only the use of benzodiazepines in the initial and most acute phase [79]. This may be because of a growing awareness of the cardiovascular risk associated with the use of amphetamines $[72,73]$ and reluctance to add to the problem by using antipsychotics which have their own cardiovascular side effects. However, the empirical evidence in this field is still limited.

The NICE guideline on the long-term treatment of psychosis with coexisting substance misuse questions whether pharmacological treatment for either disorder should be modified as a result of having the coexisting diagnosis [80]. The authors conclude that there is little robust evidence to guide the use of specific pharmacological treatment, largely because most trials conducted among people with psychosis have excluded those with coexisting substance misuse. The conclusion of the NICE guideline is, therefore, that antipsychotics should be used according to the guideline on schizophrenia [81]. The issue of cardiac adverse events is not discussed. A Cochrane review about treatment for amphetamine psychosis concludes similarly; while anti-psychotic medications are useful for the short-term relief, there is no evidence to guide decisions about long-term medical care to reduce relapse to psychosis [82]. As for non-medical interventions, a recent review recommends abstinence from amphetamine in order to prevent relapse to psychosis and to use psychosocial treatment interventions such as cognitive behavioral therapy and contingency management to reach this goal [83].

As with all dual disorders, long-term treatment should target both the psychosis and the substance use [84]. For patients with psychosis and concomitant substance use, cessation of substance use significantly increases remission of psychosis [85]. However, the traditional idea of amphetamine-induced psychosis and schizophrenia as being two clearly separate entities with different etiology is reflected in treatment choices. Whereas patients with schizophrenia are often offered both medical and psycho-social aftercare, those with amphetamine-induced psychosis are to a greater extent discharged after few days with a recommendation to abstain from substance use or often referred to a drug treatment program. Both the high mortality rate and the high rate of transition to primary psychosis should, however, urge us to follow these patients more closely both medically and for mental health.

\section{Conclusion}

The relationship between the use of amphetamines and psychosis is a complex one. The current diagnostic categories require cut-offs on two sides of the amphetamine-induced psychosis, both against the more normal expected effects of acute intoxication and withdrawal and against the more severe primary psychosis. Differentiation between these three conditions is clinically difficult. Also, diagnostic practices differ between cultures and we are uncertain whether today's taxonomy gives the most meaningful picture. Though there is substantial evidence for a dose-response relationship, at least for acute psychotic symptoms, this is probably modified by individual vulnerability. The persistence of psychotic symptoms and the diagnostic transition from substance-induced to primary psychosis suggest that some individuals are sensitized to respond with psychotic symptoms sooner and for these symptoms to last longer. The psychotic symptoms also seem to be elicited by gradually subsiding exposure. Given the high 
transition rates, amphetamine-induced psychosis should, in fact, be viewed as one of the strongest predictors of primary psychosis. Unlike many other individuals at risk of developing schizophrenia, patients with drug-induced psychosis are already identified, included in the health-care system and thus available for preventative interventions.

Treatment should aim at reducing the risk of relapse to psychosis and substance use and reducing the risk of death. We do not in fact know whether medical anti-psychotic aftercare in this population would increase or decrease their life expectancy. The risk of relapse to psychosis may be reduced, but awareness of the risk of cardiac adverse events should be maintained.

We are starting to acknowledge that amphetamine-induced psychosis is more affiliated with primary psychosis than previously assumed. This calls for adaptations in treatment. Three clinical implications can be drawn: Controlling amphetamine use is not sufficient to prevent relapse to psychosis; general life stressors should also be targeted. In cases of multiple hospitalizations for amphetamine-induced psychosis, the case of sensitization should be considered, and a new diagnostic appraisal must be carried out. In anticipation of clearer evidence, we suggest that antipsychotic medication should be used with caution for patients with psychosis and current concomitant use of amphetamines, regardless of which condition developed first.

\section{Compliance with Ethics Guidelines}

Conflict of Interest Eline Borger Rognli and Jørgen G. Bramness declare that they have no conflict of interest.

Human and Animal Rights and Informed Consent This article does not contain any studies with animal subjects performed by any of the authors. Two of the referred studies, Medhus et al. 2013 [27•] and Medhus et al. 2015 [77•], are clinical studies where the authors were co-authors (Bramness on the 2013 paper and Rognli on the 2015 paper).

\section{References}

Papers of particular interest, published recently, have been highlighted as:

- Of importance

•. Of major importance

1. Edeleano L. Über einige Derivate der Phenylmethacrylsäure und der Phenylisobuttersäure., in Berichte der Deutschen chemischen Gesellschaft zu Berlin. 1887: Berlin. p. 616-22.

2. Suwaki H, Fukui S, Konuma K. Methamphetamine abuse in Japan: its 45 year history and the current situation. In: Klee H, editor. Amphetamine misuse: international perspectives on current trends. Amsterdam: Harwood Academic Publishers; 1997. p. 199-214.

3. Prinzmetal M, Bloomberg W. The use of benzedrine for the treatment of narcolepsy. JAMA. 1935;105(25):2051-4.
4. Young D, Scoville WB. Paranoid psychoses in narcolepsy and possible danger of benzedrine treatment. Med Clin N Am. 1938;22: $637-45$.

5. UNODC. World drug report 2011. Vienna: United Nations Office on Drugs and Crime; 2012.

6. Degenhardt L, Hall W. Extent of illicit drug use and dependence, and their contribution to the global burden of disease. Lancet. 2012;379(9810):55-70.

7. Marshall BD, Werb D. Health outcomes associated with methamphetamine use among young people: a systematic review. Addiction. 2010;105(6):991-1002.

8. Grant KM et al. Methamphetamine-associated psychosis. J Neuroimmune Pharmacol. 2012;7(1):113-39. The author provides a thorough review of the phenomenon methamphetamineinduced psychosis (MAP), with description of risk factors and symptoms. The article shows the equivocal boundaries of MAP and the complexity in determining whether the psychosis is secondary to substance use or a primary psychosis in substanceusing individuals.

9. Angrist BM, Gershon S. The phenomenology of experimentally induced amphetamine psychosis - preliminary observations. Biol Psychiatry. 1970;2(2):95-107.

10. Bell DS. The experimental reproduction of amphetamine psychosis. Arch Gen Psychiatry. 1973;29(1):35-40.

11. Griffiths JD, Oates J, Cavanaugh J. Paranoid episodes induced by drug. JAMA. 1968;205:39.

12. McKetin $\mathrm{R}$ et al. The risk of psychotic symptoms associated with recreational methamphetamine use. Drug Alcohol Rev. 2010;29(4): 358-63.

13. McKetin $\mathrm{R}$ et al. The prevalence of psychotic symptoms among methamphetamine users. Addiction. 2006;101(10):1473-8.

14. McKetin R et al. Dose-related psychotic symptoms in chronic methamphetamine users: evidence from a prospective longitudinal study. JAMA Psychiatry. 2013;70(3):319-24. This longitudinal study demonstrates a strong dose-dependent increase in the occurrence of psychotic symptoms during periods of methamphetamine use among individuals who use the drug regularly.

15. Srisurapanont $\mathrm{M}$ et al. Psychotic symptoms in methamphetamine psychotic in-patients. Int J Neuropsychopharmacol. 2003;6(4): 347-52.

16. Zorick $\mathrm{T}$ et al. Withdrawal symptoms in abstinent methamphetamine-dependent subjects. Addiction. 2010;105(10): 1809-18.

17. Fasihpour B, Molavi S, Shariat SV. Clinical features of inpatients with methamphetamine-induced psychosis. J Ment Health. 2013;22(4):341-9.

18. Chen CK et al. Pre-morbid characteristics and co-morbidity of methamphetamine users with and without psychosis. Psychol Med. 2003;33(8):1407-14.

19. Kittirattanapaiboon $\mathrm{P}$ et al. Long-term outcomes in methamphetamine psychosis patients after first hospitalisation. Drug Alcohol Rev. 2010;29(4):456-61.

20. Hides L et al. Primary and substance-induced psychotic disorders in methamphetamine users. Psychiatry Res. 2015;226(1):91-6.

21. Lichlyter B, Purdon S, Tibbo P. Predictors of psychosis severity in individuals with primary stimulant addictions. Addict Behav. 2011;36(1-2):137-9.

22. Lecomte $\mathrm{T}$ et al. Predictors of persistent psychotic symptoms in persons with methamphetamine abuse receiving psychiatric treatment. J Nerv Ment Dis. 2013;201(12):1085-9.

23. Smith MJ et al. Prevalence of psychotic symptoms in substance users: a comparison across substances. Compr Psychiatry. 2009;50(3):245-50.

24. Rognli EB et al. Does the pattern of amphetamine use prior to incarceration predict later psychosis? - a longitudinal study of 
amphetamine users in the Swedish criminal justice system. Drug Alcohol Depend. 2014;143:219-24.

25. Salo R et al. Findings of preserved implicit attention in methamphetamine dependent subjects. Prog Neuropsychopharmacol Biol Psychiatry. 2008;32(1):217-23.

26. Batki SL, Harris DS. Quantitative drug levels in stimulant psychosis: relationship to symptom severity, catecholamines and hyperkinesia. Am J Addict. 2004;13(5):461-70.

27. Medhus $\mathrm{S}$ et al. A comparison of symptoms and drug use between patients with methamphetamine associated psychoses and patients diagnosed with schizophrenia in two acute psychiatric wards. Psychiatry Res. 2013;206(1):17-21. This study found no difference in positive symptoms when comparing patients with acute psychosis with and without positive testing for methamphetamine. The implication is that in the acute phase, schizophrenia and methamphetamine-associated psychosis is very difficult to tell apart. This study also speaks against a dose-response relationship between amount of methamphetamine used and the occurrence of psychotic symptoms.

28. Sato $\mathrm{M}$ et al. Acute exacerbation of paranoid psychotic state after long-term abstinence in patients with previous methamphetamine psychosis. Biol Psychiatry. 1983;18(4):429-40.

29. Sato M, Numachi Y, Hamamura T. Relapse of paranoid psychotic state in methamphetamine model of schizophrenia. Schizophr Bull. 1992;18(1):115-22.

30. Iwanami A et al. Patients with methamphetamine psychosis admitted to a psychiatric hospital in Japan. A preliminary report. Acta Psychiatr Scand. 1994;89(6):428-32.

31. Konuma K. Use and abuse of amphetamines in Japan. In: Cho AK, Segal DS, editors. Amphetamine and its analogs - psychopharmacology, toxicology and abuse. San Diego: Academic; 1994.

32. Akiyama K. Longitudinal clinical course following pharmacological treatment of methamphetamine psychosis which persists after long-term abstinence. Ann N Y Acad Sci. 2006;1074:125-34.

33. Ujike H, Sato M. Clinical features of sensitization to methamphetamine observed in patients with methamphetamine dependence and psychosis. Ann N Y Acad Sci. 2004;1025:279-87.

34. Gururajan A et al. Drugs of abuse and increased risk of psychosis development. Aust N Z J Psychiatry. 2012;46(12):1120-35.

35.• Callaghan RC et al. Methamphetamine use and schizophrenia: a population-based cohort study in California. Am J Psychiatry. 2012;169(4):389-96. This is a large, register based, longitudinal study that compares $\mathbf{4 2 . 4 1 2}$ individuals who have been hospitalized for a methamphetamine-related condition to a proxy of the normal population. The methamphetamine cohort had more than 9 times increased risk of developing schizophrenia, and this study thus demonstrates methamphetamine use as a risk factor for schizophrenia.

36.• Niemi-Pynttari JA et al. Substance-induced psychoses converting into schizophrenia: a register-based study of 18,478 Finnish inpatient cases. J Clin Psychiatry. 2013;74(1):e94-9. This study is the largest longitudinal study to investigate the transition from amphetamine-induced psychosis to primary psychosis. The eight-year cumulative risk to receive a schizophreniaspectrum diagnosis was $30 \%$. This study thus demonstrates amphetamine-induced psychosis as a relatively strong risk factor for schizophrenia.

37. Mathias S, Lubman DI, Hides L. Substance-induced psychosis: a diagnostic conundrum. J Clin Psychiatry. 2008;69(3):358-67.

38. Ding $\mathrm{Y}$ et al. Adverse childhood experiences and interaction with methamphetamine use frequency in the risk of methamphetamineassociated psychosis. Drug Alcohol Depend. 2014;142:295-300.

39. Regier DA et al. Comorbidity of mental disorders with alcohol and other drug abuse. Results from the Epidemiologic Catchment Area (ECA) Study. JAMA. 1990;264(19):2511-8.
40. Jablensky A et al. Psychotic disorders in urban areas: an overview of the study on low prevalence disorders. Aust N Z J Psychiatry. 2000;34(2):221-36.

41. Brady KT, Sinha R. Co-occurring mental and substance use disorders: the neurobiological effects of chronic stress. Am J Psychiatry. 2005;162(8):1483-93.

42. Chambers RA, Krystal JH, Self DW. A neurobiological basis for substance abuse comorbidity in schizophrenia. Biol Psychiatry. 2001;50(2):71-83.

43. Khantzian EJ. The self-medication hypothesis of substance use disorders: a reconsideration and recent applications. Harv Rev Psychiatry. 1997;4(5):231-44.

44. Wobrock T et al. Comorbid substance abuse in first-episode schizophrenia: effects on cognition and psychopathology in the EUFEST study. Schizophr Res. 2013;147(1):132-9.

45. Mauri MC et al. Substance abuse in first-episode schizophrenic patients: a retrospective study. Clin Pract Epidemiol Ment Health. 2006;2:4.

46. Green AI et al. Detection and management of comorbidity in patients with schizophrenia. Psychiatr Clin North Am. 2003;26(1): 115-39.

47. Loberg EM et al. The cannabis pathway to non-affective psychosis may reflect less neurobiological vulnerability. Front Psychiatry. 2014;5:159.

48. DeQuardo JR, Carpenter CF, Tandon R. Patterns of substance abuse in schizophrenia: nature and significance. J Psychiatr Res. 1994;28(3):267-75.

49. Helseth V et al. Substance use disorders among psychotic patients admitted to inpatient psychiatric care. Nord J Psychiatry. 2009;63(1):72-7.

50. Barnett JH et al. Substance use in a population-based clinic sample of people with first-episode psychosis. Br J Psychiatry. 2007;190: 515-20.

51. Sara GE et al. Stimulant use disorders in people with psychosis: a meta-analysis of rate and factors affecting variation. Aust $\mathrm{N} \mathrm{Z} \mathrm{J}$ Psychiatry. 2015;49(2):106-17. This meta-analysis found that among individuals with psychosis, cannabis use disorders were the strongest correlate of the prevalence of stimulant use disorders. This points to a possibility that amphetamine and cannabis together may affect and interact with psychosis.

52. Salo R et al. Attentional control and brain metabolite levels in methamphetamine abusers. Biol Psychiatry. 2007;61(11): 1272-80.

53. Chen $\mathrm{CK}$ et al. Morbid risk for psychiatric disorder among the relatives of methamphetamine users with and without psychosis. Am J Med Genet B Neuropsychiatr Genet. 2005;136(1):87-91.

54. Sulaiman AH et al. The risk and associated factors of methamphetamine psychosis in methamphetamine-dependent patients in Malaysia. Compr Psychiatry. 2014;55 Suppl 1:S89-94.

55. Petrovsky $\mathrm{N}$ et al. Sleep deprivation disrupts prepulse inhibition and induces psychosis-like symptoms in healthy humans. J Neurosci. 2014;34(27):9134-40.

56. Bell DS. Comparison of amphetamine psychosis and schizophrenia. Br J Psychiatry. 1965;111:701-7.

57. Ellinwood E. Amphetamine psychosis: I. description of individuals and process. J Nerv Ment Dis. 1967;144:273-83.

58. Bousman CA et al. Methamphetamine-associated psychosis: a model for biomarker discovery in schizophrenia in handbook of schizophrenia spectrum disorders, M.S. Ritsner, Editor. 2011, Springer: Amsterdam.

59. Curran C, Byrappa N, McBride A. Stimulant psychosis: systematic review. Br J Psychiatry. 2004;185:196-204.

60. Caton $\mathrm{C}$ et al. Differences between early-phase primary psychotic disorder with concurrent substance use and substance-induced psychosis. Arch Gen Psychiatry. 2005;62:137-45. 
61. American Psychiatric Association, Diagnostic and Statistical Manual of Mental Disorder, Fourth edition, Text Revision (DSMIV-TR). 2000, Arlington: American Psychiatric Association.

62. Akiyama K, Saito A, Shimoda K. Chronic methamphetamine psychosis after long-term abstinence in Japanese incarcerated patients. Am J Addict. 2011;20(3):240-9.

63. Hasin D et al. Diagnosis of comorbid psychiatric disorders in substance users assessed with the psychiatric research interview for substance and mental disorders for DSM-IV. Am J Psychiatry. 2006;163(4):689-96.

64. Caton CL et al. Stability of early-phase primary psychotic disorders with concurrent substance use and substance-induced psychosis. $\mathrm{Br}$ J Psychiatry. 2007;190:105-11.

65. Bramness JG et al. Amphetamine-induced psychosis - a separate diagnostic entity or primary psychosis triggered in the vulnerable? BMC Psychiatry. 2012;12:221. This article questions the validity of amphetamine-induced psychosis as a separate diagnostic entity, and suggests that the relationship between amphetamine use and psychosis is best understood within a stressvulnerability model.

66. Sato M. A lasting vulnerability to psychosis in patients with previous methamphetamine psychosis. Ann N Y Acad Sci. 1992;654: 160-70.

67. Verdoux H, van Os J. Psychotic symptoms in non-clinical populations and the continuum of psychosis. Schizophr Res. 2002;54(12):59-65.

68. van Os J et al. A systematic review and meta-analysis of the psychosis continuum: evidence for a psychosis proneness-persistenceimpairment model of psychotic disorder. Psychol Med. 2009;39(2): 179-95.

69. Ericsson E, Bradvik L, Hakansson A. Mortality, causes of death and risk factors for death among primary amphetamine users in the Swedish criminal justice system. Subst Use Misuse. 2014;49(3): 262-9.

70. Kuo CJ et al. Causes of death of patients with methamphetamine dependence: a record-linkage study. Drug Alcohol Rev. 2011;30(6): $621-8$.

71. Kaye $\mathrm{S}$ et al. Methamphetamine-related fatalities in Australia: demographics, circumstances, toxicology and major organ pathology. Addiction. 2008;103(8):1353-60.

72. Henry BL, Minassian A, Perry W. Effect of methamphetamine dependence on heart rate variability. Addict Biol. 2012;17(3):648-58.
73. Haning W, Goebert D. Electrocardiographic abnormalities in methamphetamine abusers. Addiction. 2007;102 Suppl 1:70-5.

74. Parks J et al. Morbidity and mortality in people with serious mental illness. 2006: National Association of State Mental Health Program Directors (NASMHPD) Medical Directors Council Alexandria, VA.

75. Saha S, Chant D, McGrath J. A systematic review of mortality in schizophrenia: is the differential mortality gap worsening over time? Arch Gen Psychiatry. 2007;64(10):1123-31.

76. Hennekens $\mathrm{CH}$ et al. Schizophrenia and increased risks of cardiovascular disease. Am Heart J. 2005;150(6):1115-21.

77. Medhus S et al. Amphetamine-induced psychosis: transition to schizophrenia and mortality in a small clinical sample. Am J Addict, 2015. in press. This article demonstrates similar transition rates from amphetamine-induced psychosis to schizophrenia as that found in other studies, and also finds a disturbingly high death rate.

78. Richards JR et al. Treatment of toxicity from amphetamines, related derivatives, and analogues: a systematic clinical review. Drug Alcohol Depend. 2015;150:1-13.

79. McIver $\mathrm{C}$ et al. Guidelines for the medical management of patients with methamphetamine-induced psychosis. Australia: G.o.S; 2006.

80. NICE, Psychosis with coexisting substance misuse. Clinical guideline 120, N.c.c.f.m. health, Editor. 2011: London.

81. NICE, Schizophrenia: core interventions in the treatment of and management of schizophrenia in primary and secondary care, N.c.c.f.m. health, Editor. 2009: London.

82. Shoptaw SJ, Kao U, Ling W. Treatment for amphetamine psychosis. Cochrane Database Syst Rev. 2009;1, CD003026.

83. Glasner-Edwards S, Mooney LJ. Methamphetamine psychosis: epidemiology and management. CNS Drugs. 2014;28(12):1115-26.

84. Mueser TM et al. Integrated treatment for dual disorder. A guide to effective practice. New York: The Guilford Press; 2003.

85. Lambert $\mathrm{M}$ et al. The impact of substance use disorders on clinical outcome in 643 patients with first-episode psychosis. Acta Psychiatr Scand. 2005;112(2):141-8.

86. Whitty $\mathrm{P}$ et al. Diagnostic stability four years after a first episode of psychosis. Psychiatr Serv. 2005;56(9):1084-8.

87. Crebbin $\mathrm{K}$ et al. First-episode drug-induced psychosis: a medium term follow up study reveals a high-risk group. Soc Psychiatry Psychiatr Epidemiol. 2009;44(9):710-5.

88. Pedros A et al. Two-year diagnostic stability and prognosis in acute psychotic episodes. Actas Esp Psiquiatr. 2009;37(5):245-51. 